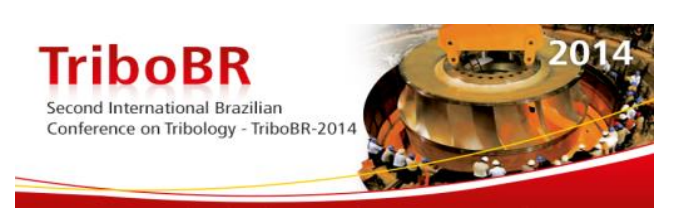

\title{
DRY SLIDING WEAR OF CA-6NM STAINLESS STEEL WITH RELATIVELY LOW SURFACE ROUGHNESS*
}

\author{
Giuseppe Pintaude ${ }^{1}$ \\ Gismar Schilive de Souza ${ }^{2}$ \\ Rogério Breganon ${ }^{3}$ \\ Silvio Francisco Brunatto 4
}

\begin{abstract}
This study aims to evaluate the effect of specimen preparation on the dry sliding wear behavior of CA-6 NM stainless steel. Two different surface finishing manufacturing processes were applied: lapping and metallographic polishing. The wear tests were conducted in reciprocating ball-on-flat system, performed for two loads: 5 or $8 \mathrm{~N}$. For all test conditions, hardmetal ball was employed as counterbody. The surfaces were evaluated using 3D interferometry technique to determine their surface roughness, including texture analysis regarding isotropy. Surface characterization results indicated the presence of texturing and preferential orientation, since the parameter Str was smaller than 0.5 for samples of both the studied conditions. Two distinct levels of isotropy evaluated through Str parameter were achieved: 0.13 for lapping and 0.3 for metallographic polishing process. It is clear from wear tests that the variation of average surface roughness is the key point for tribological behavior of CA-6 NM stainless steel.
\end{abstract}

Keywords: Sliding wear; Stainless steel; Polishing; Lapping.

1 Doctor Eng. degree, Professor, Departamento Acadêmico de Mecânica, Universidade Tecnológica Federal do Paraná, Curitiba, Paraná, Brazil.

2 Master degree, Student, Programa de Pós-Graduação em Engenharia Mecânica, Universidade Federal do Paraná, Curitiba, Paraná, Brazil.

3 Expert degree, Student, Programa de Pós-Graduação em Engenharia Mecânica, Universidade Federal do Paraná, Curitiba, Paraná, Brazil.

4 Doctor Eng. degree, Professor, Departamento de Engenharia Mecânica, Universidade Federal do Paraná, Curitiba, Paraná, Brazil.

\footnotetext{
* Technical contribution to the $2^{\text {nd }}$ International Brazilian Conference on Tribology - TriboBR 2014, November $3^{\text {rd }}$ to $5^{\text {th }}, 2014$, Foz do Iguaçu, PR, Brazil.
} 


\section{INTRODUCTION}

The tribological behavior of surfaces can be directly associated to their surface finishing. More than that, for lubricated systems the performance of materials is dependent on the isotropy of surfaces, which change in accordance with the manufacturing process, such as turning, grinding and polishing [1].

The occurrence of adhesive wear mechanism is often related to the real contact area concept. The increase of contact area during the wear process can lead to junctions formation, which can be sheared as the friction force increase, giving rise to debris formation [2].

To avoid or reduce the adhesion between surfaces, the finishing of them is a suitable variable to be altered. Besides, the mechanical properties of surfaces affect the real contact area. For instance, the increase in hardness can be reduce the contact area, and consequently, diminish the adhesion possibility [3].

The characterization of surface finishing is usually made using bi-dimensional roughness parameters. However, a bi-dimensional profile is not enough to characterize in a complete way the contact between two surfaces: it depends on the tri-dimensional characteristics [4].

The material studied in the current investigation is the alloy CA-6NM, a cast stainless steel developed to improve the weldability of martensitic stainless steels. It presents many applications, such as hydraulic rotors, pumps and compressors. In general, this alloy is employed with tempered martensite matrix containing controlled volume fractions of retained austenite [5].

The purpose of this investigation is to correlate the surface finishing with the tribological behavior of CA-6NM steel, tested under reciprocating movement in ballon-flat configuration. Two surface finishing manufacturing processes were employed to obtain relatively low surface roughness, lapping and polishing, to be tested under dry condition.

\section{MATERIAL AND METHODS}

\subsection{Material and Manufacturing of Specimens}

The tested material was the CA-6NM stainless steel, in accordance with ASTM A743 Standard [6]. Blanks of the studied steel were cut from a cast hydraulic turbine blade, which was quenched and tempered to hardness on the order of $280 \mathrm{HV}$, and a microhardness of $316 \mathrm{HV}_{0.3}$. Table 1 presents its nominal and effective chemical composition obtained by spectrometry.

Table 1. Nominal and effective chemical composition of CA-6NM stainless steel (mass \%).

\begin{tabular}{ccccccccccc}
\hline $\mathbf{C}$ & $\mathbf{C r}$ & $\mathbf{V}$ & $\mathbf{S i}$ & $\mathbf{N i}$ & $\mathbf{M n}$ & $\mathbf{M o}$ & $\mathbf{P}$ & $\mathbf{C u}$ & $\mathbf{S}$ & $\mathbf{F e}$ \\
\hline 0.06 & $11.5-$ & 0.05 & 1.00 & $3.5-$ & 1.00 & $0.4-$ & 0.04 & 0.05 & 0.03 & Balance \\
$\max$ & 14.0 & $\max$ & & 4.5 & & 1.0 & $\max$ & $\max$ & $\max$ & \\
\hline 0.013 & 12.43 & 0.05 & 0.53 & 3.32 & 0.94 & 0.38 & 0.02 & 0.40 & - & 81.87 \\
\hline
\end{tabular}

From X-Ray diffraction analysis (results not shown), the presence of acicular ferrite (cubic or tempered martensite) was confirmed as expected for the matrix phase, but no retained-austenite phase peak was evidenced, in this case.

* Technical contribution to the $2^{\text {nd }}$ International Brazilian Conference on Tribology - TriboBR 2014, November $3^{\text {rd }}$ to $5^{\text {th }}$, 2014, Foz do Iguaçu, PR, Brazil. 


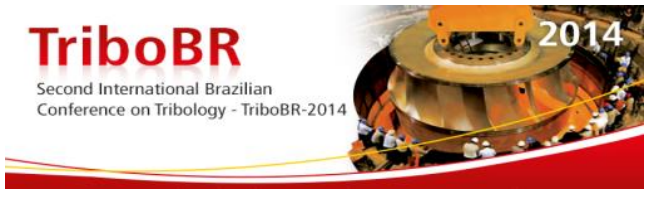

The samples were obtained as follows:

- Specimens presenting $11.5 \times 20 \times 100 \mathrm{~mm}$ (width $\mathrm{x}$ height $\mathrm{x}$ length) dimensions were cut by WED machine from a blank. Both the $20 \times 100 \mathrm{~mm}^{2}$ areas of the specimens were prepared by two different surface finishing manufacturing processes, lapping and polishing;

- Lapping of the specimens was carried out using diamond of $0.5 \mu \mathrm{m}$ average size as abrasive material, rotating against a cast iron disk, being the movement random and restricted to a specific area;

- The pressure applied during the lapping process was $8.3 \mathrm{kPa}$, and the other parameters were not informed by the supplier due to confidentiality conditions;

- Polishing was hand-made following the usual metallographic technique. After cutting, the surfaces for study were ground using 220, 320, 400, and 600 grade sandpaper. The final finishing step was performed using $1.0 \mu \mathrm{m} \mathrm{Al}_{2} \mathrm{O}_{3}$ suspension. Aiming to provide a same procedure, the polishing time of each surface was fixed in 15 minutes.

- Samples for wear testing were cut from lapped or polished specimens resulting in specimens with dimensions of $20 \mathrm{~mm} \times 11.5 \mathrm{~mm} \times 20 \mathrm{~mm}$.

3D roughness measurements were performed using CCl-Lite equipment, for white light interferometry. The following conditions were selected: Gaussian filter of $0.8 \mu \mathrm{m}$; Threshold $0.1 \%$ to remove excessive peaks and valleys; and area of measurement relative to $2.25 \mathrm{~mm}^{2}$. The indicated average values correspond to a series of three measurements. Before each surface measurement, the samples were cleaned using isopropyl alcohol.

\subsection{Wear tests}

Dry wear tests were performed at room temperature, using a tribometer CETR UMT, under reciprocating mode using $20 \mathrm{~Hz}$ as a constant frequency in a ball-on-flat configuration. Wear track was adjusted for a length of $5 \pm 0.5 \mathrm{~mm}$.

Two test loads were investigated, $5 \mathrm{~N}$ and $8 \mathrm{~N}$. For each tested load, five tests were performed for each sample, resulting in 15 worn tracks to be analyzed. For all testing condition, 4mm-diameter hardmetal balls were used as counter-body. The position of ball inside its holder was changed each test, and a new ball is replaced after 10 worn tracks.

Total testing time was fixed in $600 \mathrm{~s}$. Each average value of friction coefficient (COF) is a result of a series of 5 tests. In addition, running-in period was detected for $180 \mathrm{~s}$, and the values of COF during this period were not computed to the final average value. An example of the variation of friction values during the steady-state regime is presented in Figure 1.

* Technical contribution to the $2^{\text {nd }}$ International Brazilian Conference on Tribology - TriboBR 2014, November $3^{\text {rd }}$ to $5^{\text {th }}$, 2014, Foz do Iguaçu, PR, Brazil. 


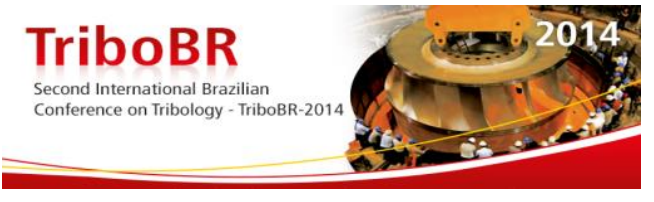

In this way, V can be calculated following Equation 1 [7],

where:

$$
V=\left[\frac{1}{2} \cdot r^{2} \cdot\left(\pi \frac{\emptyset}{180}-\sin \emptyset\right)\right] \cdot l(1)
$$

$\mathrm{V}$ is the removed volume;

$\mathrm{R}$ is the track radius;

$\Phi$ is the angle between the cross-sectional area and the base of cilindrical segment; and $L$ is the length of track.

\section{RESULTS AND DISCUSSION}

Table 2 presents the values of 3D surface roughness parameters.

Table 2. Average values of 3D surface roughness parameters for lapped and polished samples.

\begin{tabular}{lcccc}
\hline Finishing & Ssk & Sku & Sq $(\boldsymbol{\mu m})$ & Str \\
\hline Lapped & $-0.22 \pm 0.05$ & $4.11 \pm 0.09$ & $0.24 \pm 0.01$ & $0.13 \pm 0.04$ \\
\hline Polished & $-1.66 \pm 0.3$ & $9.30 \pm 1.03$ & $0.28 \pm 0.03$ & $0.30 \pm 0.02$ \\
\hline
\end{tabular}

The similarity between lapped and polished samples with respect to the average surface roughness is also observed considering the value of Sq parameter. Applying an analysis of variance following F-test, we confirmed the similarity of Sq parameter for $95 \%$ of significance. On the other hand, Str, Sku and Ssk values were considered different in this same statistical hypothesis tes

Nonetheless, the textures of lapped and polished surfaces are very different. This assertive can be verified observing the values of Str parameter. When the value of Str parameter tend to unity, it means that the surface can be considered as isotropic, while values close to zero are a result of some preferential direction. In this way, the lapped surface is anisotropic. The difference observed in this value for polished surface shows the significant difference in texture for these studied specimens, which can be confirmed by analyzing Figure 3.

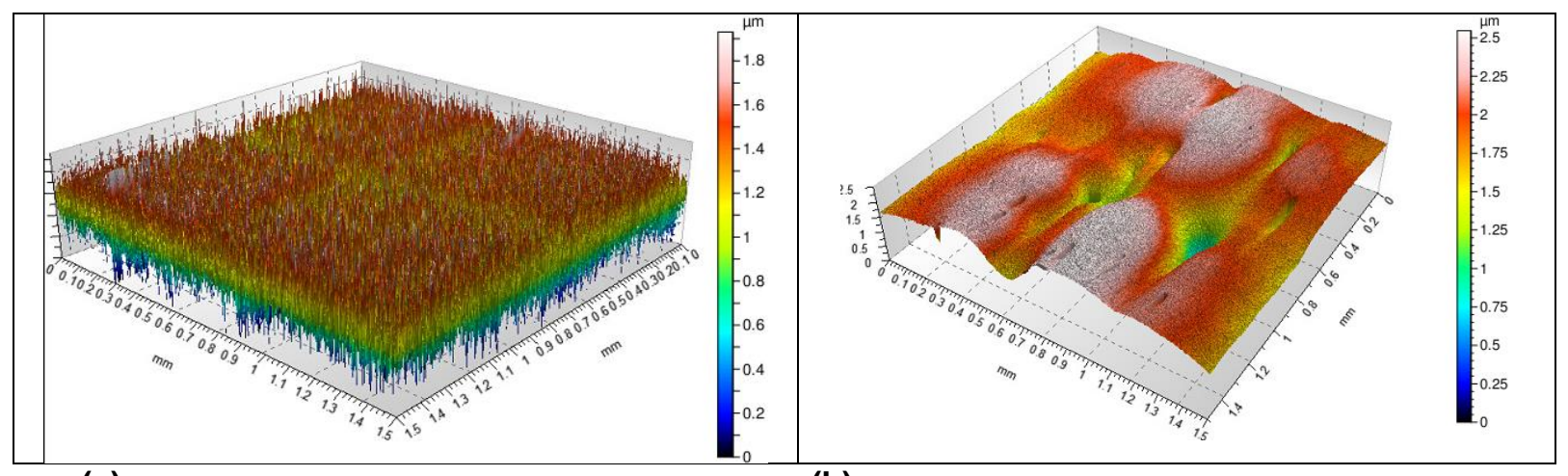

(a)

(b)

Figure 3. 3D images of tested surfaces: a) lapped sample (left), b) polished sample (right). Note the significant difference between their textures aspect.

Besides this aspect, the values of kurtosis and skewness parameters indicate the proximity of Gaussian distribution of asperities height. In both cases it is not possible to assume the surfaces as Gaussian, for Ssk<0 and Sku>3.

* Technical contribution to the $2^{\text {nd }}$ International Brazilian Conference on Tribology - TriboBR 2014, November $3^{\text {rd }}$ to $5^{\text {th }}$, 2014, Foz do Iguaçu, PR, Brazil. 
Table 3 presents the average values of friction coefficient determined after reciprocating tests.

Table 3. Average values of friction coefficient (COF) for each tested condition.

\begin{tabular}{ccc}
\hline Finishing & Load (N) & COF \\
\hline Lapped & 5 & $0.57 \pm 0.03$ \\
\hline Lapped & 8 & $0.59 \pm 0.02$ \\
\hline Polished & 5 & $0.62 \pm 0.02$ \\
\hline Polished & 8 & $0.62 \pm 0.03$ \\
\hline
\end{tabular}

The analysis of Table 3 can be made in two directions. First, verifying the effect of testing load on the COF values. Further, we can analyze the effect of finishing condition on the friction behavior. Applying the F-test of analysis of variance with $95 \%$ of significance, the testing load was considered insignificant for each finishing condition.

On the other hand, comparing the COF value for each testing load and analyzing the effect of finishing, for all cases the friction coefficient of polished surfaces can be considered higher than those determined for polished ones.

To the friction behavior can be added the wear results observed calculating the volume removed from the wear tracks. Table 4 shows the worn volume for each tested condition.

Table 4. Volume removed from wear tracks $\left(\mathrm{mm}^{3}\right)$ for each testing condition.

\begin{tabular}{lc}
\hline Test condition & $\mathbf{V}\left(\mathbf{m m}^{3}\right)$ \\
\hline Lapped $(5 \mathrm{~N})$ & 0.2638 \\
\hline Lapped $(8 \mathrm{~N})$ & 0.3639 \\
\hline Polished $(5 \mathrm{~N})$ & 0.3859 \\
\hline Polished $(8 \mathrm{~N})$ & 0.4161 \\
\hline
\end{tabular}

As observed in friction coefficients, the polished samples presented the highest values of worn volume. Besides, the applied load was significant for the calculated wear, differently from its effect on the friction behavior.

To understand the differences in tribological behaviors, the worn tracks were observed in scanning electron microscope, as well as the surface roughness of worn surfaces was also determined.

Figure 4 shows the worn surfaces of lapped samples, while in Figure 5 the worn tracks of polished ones are presented.

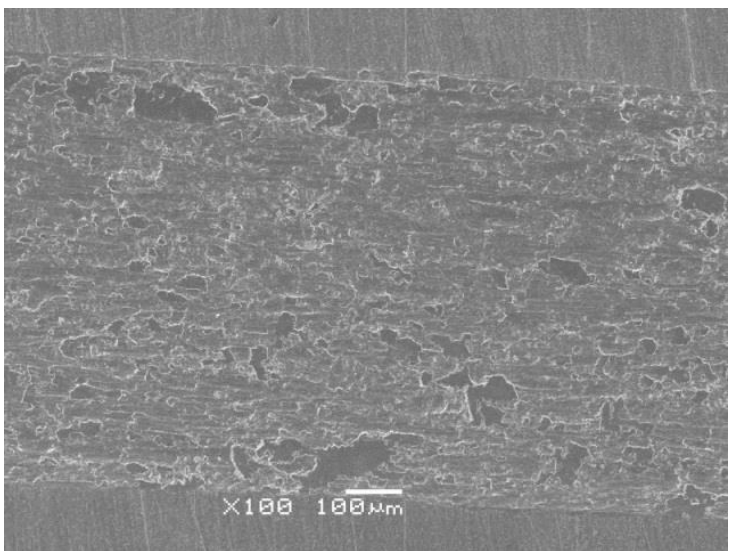

(a)

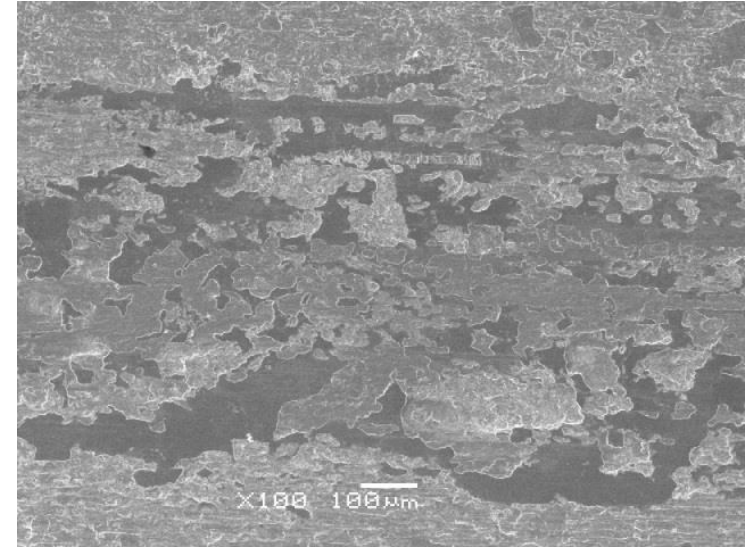

(b)

Figure 4. Worn track of lapped samples: a) tested with $5 \mathrm{~N}$, and b) tested with $8 \mathrm{~N}$.

* Technical contribution to the $2^{\text {nd }}$ International Brazilian Conference on Tribology - TriboBR 2014, November $3^{\text {rd }}$ to $5^{\text {th }}$, 2014, Foz do Iguaçu, PR, Brazil. 


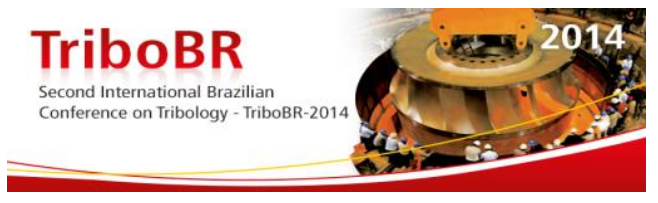

The texture of surfaces was completely modified after wear testing. With respect to the direction effect, all worn surfaces observed in Figures 4 and 5 losses their initial characteristics, described by the Str value, for example. This result is a direct effect of the intense adhesive mechanism, clearly observed in all testing conditions as a result of plastic deformation. The deformation created a crater, revealed in 3D interferometry image, as shown in Figure 2.

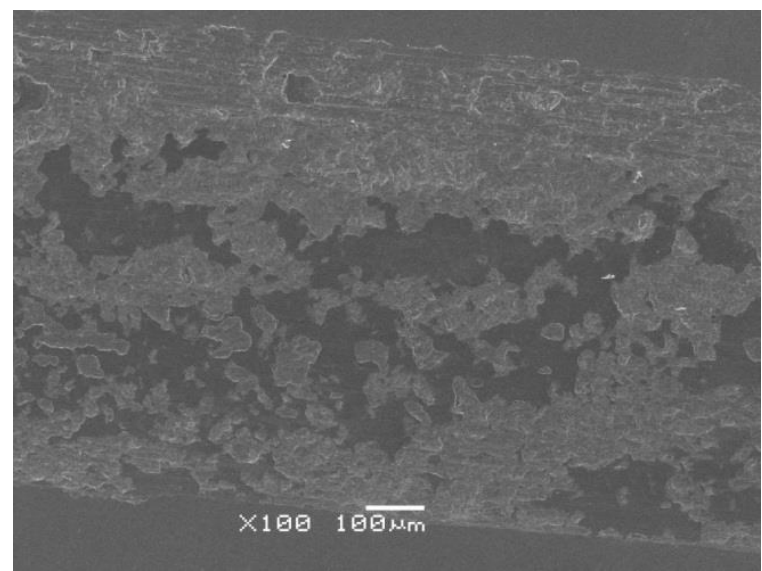

(a)

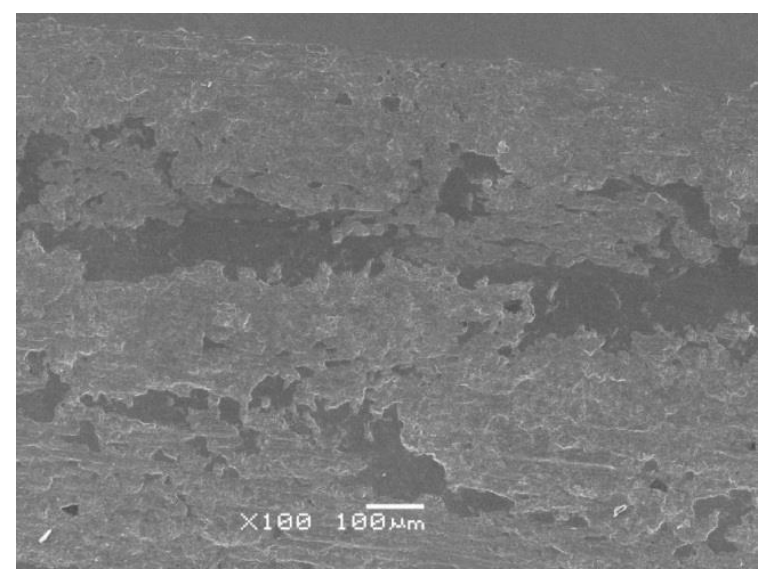

(b)

Figure 5. Worn track of polished samples: a) tested with $5 \mathrm{~N}$, and b) tested with $8 \mathrm{~N}$.

In the investigation described in [1], four different surfaces (ground, honed, hard turned, and isotropic finished) were conducted in a sliding using ball-on-flat configuration under lubricated regime. In that work, the authors found a correlation between friction coefficient and two 3D surface roughness parameters, Sq and Sds. In their experiments, both the ball and flat were made of hardened bearing steel AISI 52100 (approximately $60 \mathrm{HRc}$ ).

Therefore, differently from that proposed by Singh et al. [1] for lubricated wear, the initial values of surface roughness will not work to correlate tribological behavior with roughness. Here, we should try to correlate friction behavior and worn volume with the final values of roughness or even with the variation observed in roughness after the wear tests. Table 5 presents the values of 3D surface roughness parameters after wear testing.

Table 5. Values of 3D surface roughness of worn tracks.

\begin{tabular}{|c|c|c|c|c|c|c|c|c|}
\hline $\begin{array}{l}\text { Test } \\
\text { Condition }\end{array}$ & $\begin{array}{c}\text { Sq } \\
\text { Initial }\end{array}$ & $\begin{array}{c}\mathrm{Sq} \\
\text { track }\end{array}$ & $\begin{array}{c}\text { Ssk } \\
\text { Initial }\end{array}$ & $\begin{array}{c}\text { Ssk } \\
\text { track }\end{array}$ & $\begin{array}{c}\text { Sku } \\
\text { Initial }\end{array}$ & $\begin{array}{c}\text { Sku } \\
\text { track }\end{array}$ & $\begin{array}{c}\text { Sds }(1 / \mathrm{mm} 2) \\
\text { initial }\end{array}$ & $\begin{array}{c}\text { Sds }(1 / \mathrm{mm} 2) \\
\text { track }\end{array}$ \\
\hline $\begin{array}{l}\text { Lapped } \\
(5 N)\end{array}$ & \multirow{2}{*}{0.24} & 1.24 & \multirow{2}{*}{-0.22} & -0.30 & \multirow{2}{*}{4.11} & 3.461 & \multirow{2}{*}{19014} & 19154 \\
\hline $\begin{array}{l}\text { Lapped } \\
(8 \mathrm{~N})\end{array}$ & & 1.40 & & -1.08 & & 4.91 & & 19739 \\
\hline $\begin{array}{l}\text { Polished } \\
(5 N)\end{array}$ & \multirow{2}{*}{0.28} & 1.82 & \multirow{2}{*}{-1.66} & -0.48 & \multirow{2}{*}{9} & 7 & \multirow{2}{*}{14164} & 20073 \\
\hline $\begin{array}{l}\text { Polished } \\
(8 \mathrm{~N})\end{array}$ & & 2.26 & & -0.60 & & 14 & & 20651 \\
\hline
\end{tabular}

Considering the variation in Ssk and Sku values, it is possible to verify that the highest changes occurred for the polished surfaces. In the case of skewness, their initial value was one order of magnitude higher than that determined for lapped surfaces. After wear testing, this difference became much smaller.

* Technical contribution to the $2^{\text {nd }}$ International Brazilian Conference on Tribology - TriboBR 2014, November $3^{\text {rd }}$ to $5^{\text {th }}$, 2014, Foz do Iguaçu, PR, Brazil. 


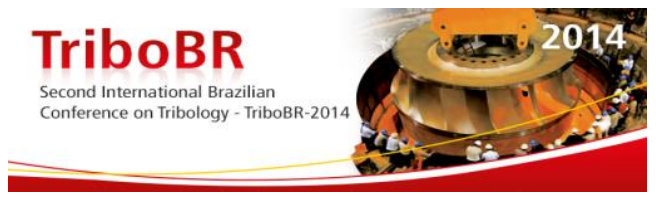

On the other hand, the similarity observed for the average roughness parameter $\mathrm{Sq}$ is relatively lost after wear tests, meaning that this parameter can be used to express the observed differences in tribological behavior.

Differently of the trend in the Sds parameter observed by Singh et al. [1], this parameter almost did not vary after the wear testing, because all initial surfaces have a relatively low roughness. Thus, in order to apply some correlation between tribological behavior and a combination of Sq and Sds parameters, we describe only the relation between wear and friction behavior with the variation of Sq parameter (Figure 6). The result works relatively well: the higher the variation, the higher the friction coefficient and the wear volume.

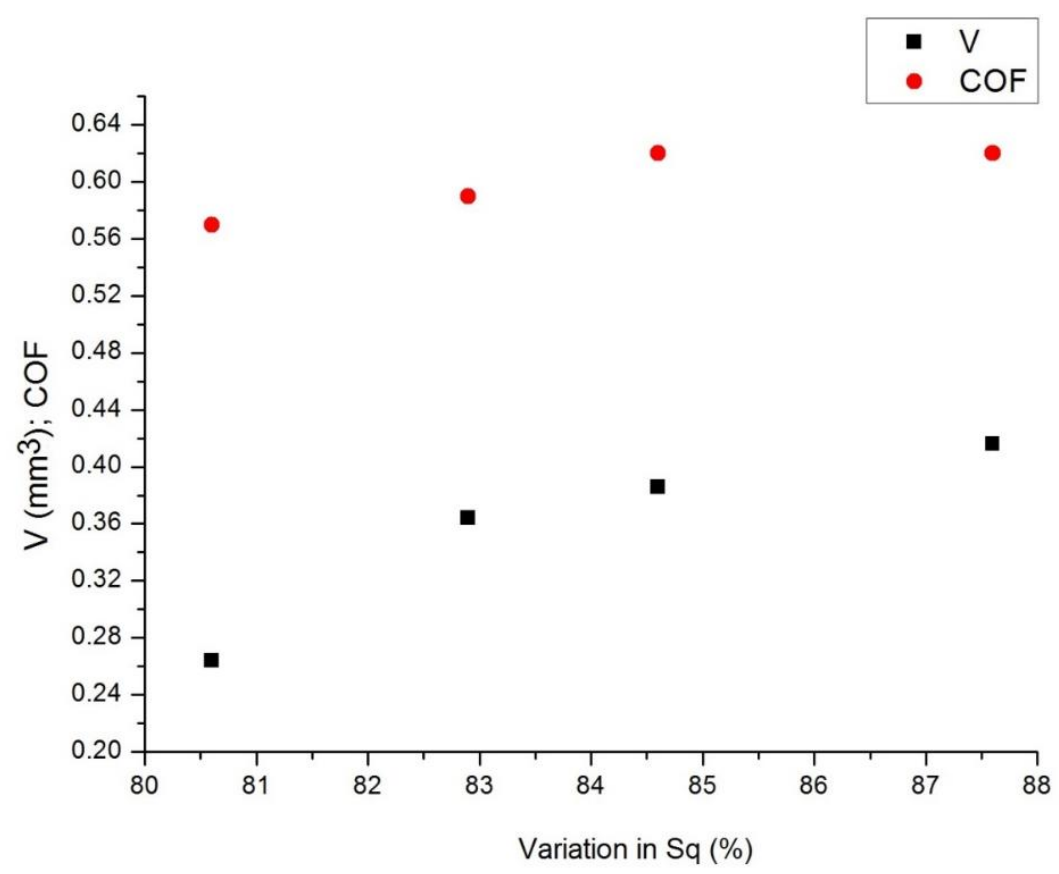

Figure 6. Effect of variation on Sq roughness parameters on the friction coefficient and wear volume values.

Eventually, it is interesting note that the friction and the wear are well related following results of Figure 6, a trend that can be also extracted from Tables 4 and 5.

\section{CONCLUSIONS}

Considering the effect of surface finishing on the tribological behavior of stainless steel CA-6NM, tested under reciprocating movement in ball-on-flat equipment, the following conclusions can be presented:

1. Polished samples presented higher friction coefficient and higher wear than those presented by lapped ones;

2. Adhesive wear was the predominant mechanism of material removal, with an intense plastic deformation; changing significantly the initial surface roughness; and

3. Friction and wear behavior under dry condition could not be correlated with the initial surface roughness, but the variation of $\mathrm{Sq}$ parameter can be associated to both tribological results.

* Technical contribution to the $2^{\text {nd }}$ International Brazilian Conference on Tribology - TriboBR 2014, November $3^{\text {rd }}$ to $5^{\text {th }}$, 2014, Foz do Iguaçu, PR, Brazil. 


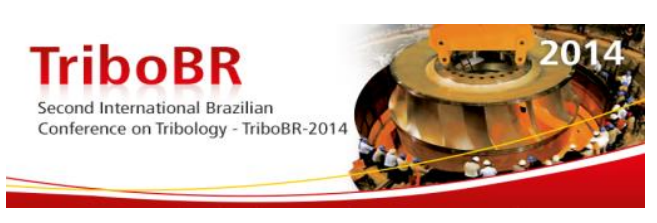

\section{Acknowledgments}

This work was supported by CNPq Brazilian Agency and FINEP. The authors would like to thank Spectroscan Co. by chemical analysis of the studied material, the Praxair Surfaces of Brazil by lapping of the samples, and IFPR-Câmpus Paranaguá for X-Ray analysis.

\section{REFERENCES}

1 Singh R, Melkote SN, Hashimoto F. Frictional response of precision finished surfaces in pure sliding. Wear. 2005;258:1500-1509.

2 Mishina $\mathrm{H}$, Hase $\mathrm{A}$. Wear equation for adhesive wear established through elementary process of wear. Wear. 2013;308:186-192.

3 Hatami S, Nafari A, Nyborrg L, Jelvestaan U. Galling related surface properties of powder metallurgical tool steels alloyed with and without nitrogen. Wear, 269:229-240, 2010.

4 Waikar RA, Guo YB. A comprehensive characterization of 3D surface topography induced by hard turning versus grinding. J. Mater. Proc. Technol. 2008;197:189-199.

5 Allenstein AN, Lepienski CM, Buschinelli AJ de A, Brunatto FS. Plasma nitriding of CA6NM steel: Effect of $\mathrm{H} 2+\mathrm{N} 2$ gas mixtures in nitriding layer formation for Low N2 contents at 500C. Mater. Res., 200;13:557-562.

6 ASTM A743/A743M-03. Historical Standard: ASTM A743/A743M-03 Standard Specification for Castings, Iron-Chromium, Iron-Chromium-Nickel, Corrosion Resistant, for General

Application.<http://enterprise.astm.org/filtrexx40.cgi?HISTORICAL/A743A743M03.htm>.

7 Sharma S, Sangal S, Mondal K. On the optical microscopic method for the determination of ball-on-flat surface linearly reciprocating sliding wear volume. Wear. 2013;300(1):82-89.

* Technical contribution to the $2^{\text {nd }}$ International Brazilian Conference on Tribology - TriboBR 2014, November $3^{\text {rd }}$ to $5^{\text {th }}$, 2014, Foz do Iguaçu, PR, Brazil. 